\title{
VÍCTOR DE LA SERNA ESPINA: VIAJERO AQUIESCENTE DEL FRANQUISMO
}

\author{
JAVIER TORRE \\ University of Denver \\ jtorre@du.edu
}

\section{RESUMEN}

La crítica de literatura viajera ha subrayado el valor de los testimonios de los escritores del realismo social de los años cincuenta, aquellos viajeros que retrataban los aspectos más feos y desolados de la realidad rural española. Sin embargo, no se puede poseer una imagen completa de la función y el alcance de la literatura viajera de los años cincuenta y sesenta si se ignora a los autores cuyos textos defendían otra mirada hacia el país, una mirada satisfecha, orgullosa y patriótica. Víctor de la Serna Espina (Valparaíso 1896 - Madrid 1958) es el máximo exponente de una literatura de viajes propagandística que alaba la labor del régimen y defiende su modelo social y cultural, al tiempo que promueve su ideal de identidad nacional construyendo una "comunidad imaginaria".

En el presente ensayo se estudia su obra viajera, específicamente se analizan los aspectos estilísticos, temáticos e ideológicos de su libro Nuevo viaje de España. La ruta de los foramontanos (1955). Asimismo, se estudia la estrecha relación que existió en los años cincuenta y sesenta entre la literatura viajera y el aparato propagandístico del régimen, especialmente en lo referente al respaldo que el régimen franquista dio al turismo internacional.

PALABRAS CLAVE: De la Serna; viajes; franquismo; realismo social; turismo; propaganda.

\section{VÍCTOR DE LA SERNA ESPINA: SPANISH TRAVELER SYMPATHETIC TO FRANCO'S REGIME}

\section{ABSTRACT}

The 1950s testimonial travel writing by the authors of the Social Realism movement has received much critical attention. Nevertheless, in order to understand the literary production of that time period we must also study the authors that defended a different point of view, the authors that offered a satisfied, proud and patriotic view of the country.

Víctor de la Serna Espina (1896-1958) is the most prominent representative of the propagandistic travel writing that praises the Franco regime and defends its social and cultural model, while at the same time promotes his ideals of national identity and builds an "imaginary community."

This essay studies De la Serna's travel narratives, specifically analyzing stylistic, thematic and ideological aspects of his book Nuevo viaje de España. La ruta de los foramontanos (1955). Likewise, this essay studies the close relationship that existed during the 1950s and 60s between travel narratives and the propagandistic apparatus of the Franco regime, especially in regards to developing the image of Spain as an appealing destination for international tourism.

KEY WORDS: Víctor de la Serna; travel; Franco; social realism; tourism; propaganda.

La crítica de literatura viajera se ha dedicado fundamentalmente a subrayar el valor de los testimonios de los escritores del realismo social de los años cincuenta, aquellos viajeros que retrataban los aspectos más feos y desolados de la realidad rural española e incluso se atrevían a denunciar, veladamente, los 
abusos del régimen franquista. Se suele considerar el Viaje a la Alcarria (1948), de Camilo José Cela, la obra pionera que bajo la dictadura propuso contar las "verdades de a puño" del campo español. A Cela le siguieron otros autores como Juan Goytisolo (Campos de Níjar, 1960; La Chanca, 1962), Antonio Ferres y Armando López Salinas (Caminando por las Hurdes, 1960), Antonio Ferres (Tierra de Olivos, 1964) y Jesús Torbado (Tierra mal bautizada, 1969). A medida que pasaban los años, esta literatura de denuncia se hizo más arriesgada y desafiante en la manera en que mostraba las zonas olvidadas del país (Gil Casado 1973: 423).

Sin embargo, no se puede poseer una imagen completa de la función y el alcance de la literatura viajera de los años cincuenta y sesenta si no se tiene en cuenta a esos otros escritores - los que llamaré los viajeros aquiescentes del franquismo-cuyos textos defendían otra mirada hacia el país, una mirada satisfecha, orgullosa y patriótica. Algunos de estos escritores publicaron reportajes de viaje en el semanario fascista El Español durante los años cincuenta; otros, como Jiménez Caballero, escribían crónicas poéticas con motivo de los viajes de Franco a distintas provincias españolas; todos producían un discurso apologético del régimen (Champeau 2004: 77).

Víctor de la Serna Espina (Valparaíso 1896 - Madrid 1958) es el escritor que nos sirve en el presente ensayo como botón de muestra de este tipo de escritura. Apenas existe bibliografía sobre su obra, no obstante, para un cabal entendimiento de la batalla ideológica que se libró en la década de los cincuenta dentro del género de los libros de viajes es necesario prestar atención a sus libros.

En las próximas páginas se analizan los aspectos estilísticos, temáticos e ideológicos que convierten a Víctor de la Serna en escritor paradigmático de los "viajeros aquiescentes del franquismo". Asimismo, este ensayo estudia la estrecha relación que existió en los años cincuenta y sesenta entre la literatura viajera y el aparato propagandístico del régimen, especialmente en lo referente al respaldo que el régimen franquista dio al turismo internacional como salida de la tesitura económica en que se encontraba con la práctica de la autarquía. Los libros de Víctor de la Serna se convierten así en el máximo exponente de una literatura de viajes propagandística que alaba la labor del régimen y defiende su modelo social y cultural, al tiempo que promueve su ideal de identidad nacional construyendo una "comunidad imaginaria" (en términos de Benedict Anderson) adecuada a su ideología.

En este ensayo comentaré fundamentalmente el texto Nuevo viaje de España. La ruta de los foramontanos (1955), que obtuvo el Premio Nacional de Literatura ese mismo año. El proyecto del autor se constituía como una actualización del famoso libro Viaje de España de don Antonio Ponz, un libro de viajes del siglo XVIII que, debido a su extensión (18 volúmenes) y a su erudición, se considera el más sobresaliente de los libros de viajes ilustrados. Desgraciadamente, el prematuro fallecimiento de Víctor de la Serna frustró la 
que era, sin duda, una ambicioso proyecto: en sus borradores se incluía un mapa donde tenía marcadas las regiones naturales que pretendía abarcar en su obra, que incluían la Ribera del Ebro, las Encartaciones, la Sierra de Cazorla, la Marisma del Guadalquivir...

El autor llegó a escribir un segundo libro de la serie, titulado Nuevo viaje de España. La vía del calatraveño, que se publicó en 1960, un año después de su muerte. En este segundo tomo se agrupan crónicas de viajes sobre La Mancha y la Marina de Andalucía. En mi estudio haré también algunas referencias a este libro.

Un tercer libro de Víctor de la Serna que empleo en mi análisis es España, compañero (1965). Se trata de una antología de textos periodísticos (muchos de ellos viajeros) que recopiló Alfonso de la Serna como homenaje a su padre, el libro lo publicó la editorial Prensa Española en 1964. De entre los ensayos de este libro destaca uno, donde Víctor de la Serna explica los motivos del viaje que narra en su primer libro, La ruta de los foramontanos (1955).

\section{Motivos Del Viaje}

La idea del viaje surgió a partir de un diálogo acerca de España que tuvo lugar en las páginas del $A B C$ en el que debatían el escritor José María Gironella y el director del periódico, Torcuato Luca de Tena. Víctor de la Serna terció en la conversación sobre España con un artículo titulado "Esa bella desconocida". En su artículo Víctor aboga por un mejor conocimiento del país, y de paso niega que hayan sido los Krausistas quienes han descubierto (literariamente) España, honor que le concede a Marcelino Menéndez Pelayo por sus estudios sobre España y los españoles. Más importante aún, el periodista propone, con pautas muy claras, lo que debe hacer, y lo que no, un buen escritor de viajes a la hora de salir a describir España, "esa bella desconocida".

El artículo (que no está publicado en el libro Nuevo viaje de España. La ruta de los foramontanos, sino recogido en la antología España, Compañero) es una auténtica poética del libro de viaje, y hay algunos párrafos que merecen un comentario detallado. El más notable es el siguiente:

Hay que salir en busca de España, no a gozarse en su atraso y a gozarse en lo pintoresco de su incomodidad; ni hay que hurgar en su pobreza como un buscador de basuras; ni hay que recorrerla como un coleccionista de ruinas; ni salir por ahí con un taco de pan y chorizo, decididos a hacer "tremendismo", en buscar de monstruos en las fondas malas y sin gracia, para incorporarlos a una estética de esparto y "cocos" (Serna 1965: 186).

El párrafo es toda una declaración de principios y un rechazo rotundo de varias tendencias literarias anteriores o contemporáneas al autor. El desdén abarca desde el pintoresquismo practicado por tantos escritores extranjeros del siglo XIX hasta el tremendismo de la escuela española (Cela y demás).

La referencia al tremendismo celiano es inevitable. El tremendismo lo inaugura Cela en 1942 con su novela La familia de Pascual Duarte, que aunque no 
es un libro de viajes, sí es una novela que describe, descarnadamente, la sociedad rural española. Aunque el libro de viajes que Cela publica en 1948, Viaje a la Alcarria, no se adscribe directamente al tremendismo, sí hay en él "fondas malas y sin gracia", y una cierta estética que se pudiera describir como "de esparto y cocos". El libro adopta posturas disidentes (Champeau 2004: 77) aunque carece de dimensión social y testimonial (Gil Casado 1973: 423). En cualquier caso, lo que Víctor de la Serna rechaza es una estética feísta que, con demasiada frecuencia, se había empleado para pintar a España.

La otra línea literaria y estética a la que Serna se refiere, sin nombrarla, es la larga tradición de viajeros extranjeros por España, aquellos que buscaban lo pintoresco. Autores románticos como Washington Irving, George Borrow o Theophile Gautier. Escritores y artistas más fascinados con una imagen literaria y romántica de España que con lo que allí realmente ocurría. Estos autores y otros son los responsables de recrear una España pintoresca poblada de gitanos, toros y Cármenes (Colmeiro 2002, Gifra-Adroher 2000). Este pintoresquismo españolista es el que pretende combatir Víctor de la Serna, con una representación fidedigna de lo que él considera la España real.

Por último, Serna nombra también en la carta a los Krausistas, quienes a comienzos del siglo $x x$ ya habían desarrollado una precisa concepción $\mathrm{y}$ práctica del viaje subrayando su función educadora y regeneradora de la sociedad (Ortega Cantero 1988). Curiosamente, lejos de respaldar el valor de su propuesta, Serna los vitupera con desdén (esos "caballeros esterilizados" "remilgados, pasteurizados y un poco snobs"), pues los considera dentro del grupo de autores que no han sabido o querido resaltar lo valioso de España y han preferido enfocarse en los aspectos más dolorosos, así afirma que ellos "tomaban a España un poco como con guantes de goma" (usa aquí la metáfora del escritor/médico que trata los males del país) y "sembraron de congoja nuestra alma inocente de españoles" (refiriéndose a su visión crítica y negativa, según Serna).

Después de despacharse a gusto con los tres precedentes literarios de escritura viajera y reflexión sobre el país, sostiene el autor que cualquier visión parcial está abocada al fracaso; no hay que recorrer España "como un geógrafo, como un minero, como un arqueólogo... Ni siquiera como solamente artista" (Serna 1965: 186). También declara cuál debe ser el objetivo principal del escritor de viajes:

A España hay que enseñársela a los españoles-perdón-"periodísticamente". Sólo nosotros [los periodistas] estamos calculados para la explicación popular de la universalidad española [...] Hay que confiar al periodismo la empresa de "poner en valor" España, de diagnosticar sus focos de interés y de proponer el sistema de su conocimiento ocular (Serna 1965: 187).

Por último, el periodista liga su labor de escritura al resurgimiento económico de España y a la importancia del turismo: 
Nosotros [los periodistas] creemos lo que creía Roosevelt cuando escribía a Carlton Hayes, diciéndole que esperaba que del turismo saldrían divisas bastantes para reparar los estragos de nuestra guerra (Serna 1965: 187).

Y concluye: "La Hermosa Desconocida está esperando vuestra mano de periodistas. Yo creo que acabaréis porque los españoles se aprendan España".

De la carta de Víctor de la Serna se desprenden tres ideas principales:

1) que España ha sido y continúa siendo mal retratada, por escritores y viajeros que se enfocan injustamente en los aspectos más desagradables (la modalidad pintoresca de los viajeros extranjeros, la regeneracionista de los Krausistas $-\mathrm{y}$, por extensión, de los noventayochistas -, y la tremendista de Cela y sus seguidores);

2) que el turismo es la tabla de salvación de la economía española; y

3) que la literatura periodística viajera tendrá un papel fundamental en la reactivación del turismo, mediante la descripción de lo que se debe ver y valorar del país.

Como respuesta a la carta de Víctor de la Serna, el director del $A B C$ desafió cordialmente a De la Serna para que llevara a cabo esa descripción. Serna aceptó el reto comprometiéndose a escribir un artículo diario para el $A B C$ mientras viajaba. Así se gestó su viaje y su libro: cuarenta artículos que equivalían a cuarenta jornadas, publicados primero en el diario $A B C$ y luego recogidos en un solo volumen, el Nuevo viaje de España. La ruta de los foramontanos. Adalid de estos aires de cambio y apertura, Víctor de la Serna se lanzó a los caminos de España, para contarla y hacerla más apetecible.

Víctor de la Serna prefirió satisfacer su natural inclinación hacia las letras cultivando el periodismo en vez de la ficción novelesca. Aunque a veces apresurada, su prosa es resuelta y precisa, destila erudición aunque la refrena con un estilo coloquial, en el que frecuentemente interpela al lector con la expresión compañero o amigo. En el libro, narrado en primera persona, esta constante interpelación al lector funciona como un recurso para ganarse su confianza, para mostrarse no como un pedante sabelotodo, sino como un caminante campechano que disfruta de su entorno e invita a conocerlo.

A nivel ideológico, se trata de una literatura henchida de españolismo, exaltado examen de los valores históricos, religiosos y económicos del país, con una rimbombante retórica y una imaginería y fraseología que linda en lo panfletario. Sus libros de viaje son el equivalente - salvando las diferencias - a la literatura escrita en la inmediata posguerra por escritores como Luís Rosales, José María Pemán o su propia madre, Concha Espina, afines todos al régimen franquista.

Pero más que nada, el libro de Víctor de la Serna es un libro a la defensiva, donde el objetivo fundamental es desmentir lo que se ha afirmado en anteriores libros de viajes (escritos por extranjeros y también por españoles) sobre España. Esto queda resumido en el prólogo del libro, donde el autor afirma que su intención es simplemente decir a sus lectores: 
España no es un país trágico y tremebundo poblado de unos seres desmesurados, o enanos o gigantes, o místicos o criminales. Ni un país desolado sembrado de ruina, con gitanos, asnos y cabreros; ni un pueblo de analfabetos, de sacamantecas o de hidalgos cascarrabias y dueñas enlutadas, sino un país vivo, fresco, elástico (Serna 1955: 28).

Los planteamientos ideológicos de Víctor de la Serna en sus libros de viajes son muy marcados y coinciden exactamente con el giro en la política turística y cultural que toma el régimen franquista en los años cincuenta. Sasha D. Pack, en su libro Tourism and Dictatorship (2006), ha documentado bien esa transición. Tras una década de practicar una infructuosa política autárquica, que incluía fronteras herméticamente cerradas y desconfianza del visitante extranjero (sospechoso de ser un revolucionario antifranquista $\mathrm{o}$, cuando menos, de pretender importar su liviana moral), el régimen fue cediendo a las presiones de diplomáticos y tecnócratas españoles y su tímida corriente aperturista. Como consecuencia, el ministerio del Interior, a través de la Dirección General de Turismo (DGT), acepta abrir sus fronteras al resto del mundo $\mathrm{y}$, mediante campañas publicitarias, intenta atraer ese turismo. Asimismo, Franco creó el Ministerio de Información y Turismo en 1951, una de la razones fue que este ministerio podría complementar a la censura y ser un importante instrumento propagandístico (Pack 2006: 65).

El plan Nacional de Turismo, delineado en 1952, establecía lo siguiente:

intelligently guide [the tourist's] steps, avoiding deceptions and inconveniences, given that it is necessary not only to have tourist who visit us return, but also to have them become active propagandists for our Nation, thereby enhancing our prestige in the World (citado en Pack 2006: 66).

El libro de Víctor serviría para guiar a esos turistas, nacionales e internacionales, por la senda hispánica que mejor representa los valores nacionales. El viaje descrito por el escritor en Nuevo viaje de España. La ruta de los foramontanos (1955) le lleva desde Mazcuerras, un pueblo situado a una hora de Santander, pasando por Bárcena Mayor, Reinosa, Cervatos y otras importantes poblaciones de lo que hoy es Cantabria, hasta lugares como Frómista, Vivar del Cid, Toro, Tordesillas, León y otros situados en la región de Castilla-León. Víctor de la Serna identifica Mazcuerras, el lugar donde comienza su viaje, como la "Malacoria" mencionada en los documentos medievales y que consta como el lugar de donde partieron los foramontanos en su ruta hacia el sur. Los foramontanos son los repobladores cristianos de Castilla que, después de haberse replegado en La Montaña escapando de la penetración árabe ("millares de visigodos apretujados por la presión sarracena" [Serna 1955: 50]), vuelven a la meseta en una emigración repobladora que se inicia en el siglo IX, y que avanza al paso de la Reconquista.

El tono del capítulo introductorio es épico y bien pronto se reconoce en la adjetivación grandilocuente la retórica fascista que se había impuesto en la España de los primeros lustros de la dictadura. Considera Víctor de la Serna 
que en Malacoria debería ponerse una placa con la siguiente leyenda: "Aquí empieza esa cosa inmensa e indestructible que llamamos España" (1955: 30). A renglón seguido Serna ofrece las coordenadas geográficas y étnicas de su definición de España: "Estamos en Malacoria, uno de esos Valles incontaminados del sarraceno que cobijaron a los labriegos, a los monjes y a los artesanos visigóticos" (1955: 30). A los foramontanos, los castellanos refugiados en el norte de España, se refiere más adelante como "la más vieja raza de españoles", la misma que siglos antes se enfrentara a los romanos (1955: 58).

La elección del trayecto del viaje no es casual, ni se justifica tampoco porque la familia del autor procediera de esa región. Responde a la intención de reivindicar el pedigrí europeo de España y desdecir el sólido cuerpo de literatura viajera sobre España escrita por extranjeros que insiste en ver en ella al "otro" oriental, a través de los restos arquitectónicos y de costumbres que perviven de la cultura árabe en España.

A tal grado había llegado la identificación de la Andalucía orientalizada con España que ya Azorín había lo había criticado, con no poco sarcasmo:

Los viajeros de tierras extrañas que entran en España y dan un vistazo a Fuenterrabía, ya ven en los balcones de esa villa un reflejo de Oriente. Para el francés o el británico que vienen a España ansiosos de encontrar color y de verse metidos en peligrosas aventuras, ya en Fuenterrabía se sienten dentro del misterioso y terrible Oriente (Azorín 1968: 479).

Y no era Azorín el único en notar esta falsificación, antes que él, Cenac Moncaut, viajero francés del siglo XIX, se había quejado también de la deformante transfiguración en términos muy parecidos:

Los viajeros que se dirigen a España - comenta Cenac Moncaut - tienen tal prisa por soñar a la sombra de los sicómoros de Granada y de bañarse en las poéticas aguas del Guadalquivir, que atraviesan las provincias pirenaicas desdeñando mirar en torno suyo hasta llegar a Madrid. Dijérase que España comienza en la cuenca del Tajo, y que solamente Andalucía merece ser visitada... No faltan turistas dispuestos a sostener esta extraña paradoja, así es que nadie se ha dignado dedicar un relato a Navarra, Aragón o Cataluña (citado en Burgo 1963: 115).

Por esa razón Víctor de la Serna comienza su viaje por España en el norte, que en su lectura (y también en la historiografía del régimen franquista) se identifica con la cuna histórica y étnica de España. Por esa razón también, insiste en destacar el pedigrí europeo de los españoles.

\section{AfÁn europeísta}

En esa época era problemática, y estaba sujeta a revisión, la interpretación histórica de la identidad nacional. En las fechas en que se escribe esta obra es cuando más viva está la polémica entre el profesor Américo Castro y su defensa de una España plural (judíos, moros y cristianos) y "diferente" del resto de Europa; frente a la visión católica, unitaria y "europea" de Sánchez Albornoz (Gómez-Martínez 1975). Víctor de la Serna adopta claramente la lectura 
histórica de Albornoz, de hecho menciona a Sánchez Albornoz y a Menéndez Pelayo en el texto como las dos autoridades incuestionables con respecto a cuestiones históricas.

La DGT hizo popular en los años cincuenta y sesenta el eslogan "Spain is different". Sin embargo, es necesario apuntar que desde el primer momento hubo ya un esfuerzo institucional por medir el alcance del aserto subrayando que la aducida diferencia no era tan grande. Un ejemplo notable de esto es el mensaje introductorio publicado en la guía de España de British Railways en 1950:

You have a unique experience in store for you-because Spain is the country that is "different"; yet, at the same time, you will notice in the Spanish people characteristics, which are remarkably similar to your own, as befits two very ancient peoples steeped in the same European culture (citado en Pack 2006: 69).

El fragmento muestra bien la duda e indecisión de la DGT en aquellos años: por un lado, apostar por un modelo turístico de "Flamenco, gitanos y corridas de toros" basado en la diferencia española; por otro lado, presentar una España de rasgos esencialmente europeos (con el riesgo de perder el atractivo turístico que significa comercializar la "otredad" española). Dos cosas hacían de España un país "diferente" en Europa: su historia (el único país europeo con siglos de presencia y dominación árabe) y su situación política presente (una dictadura rodeada de democracias), La cuestión era, ¿cómo desarrollar una industria turística partiendo de estos condicionantes?

El rasgo histórico que hacía a España diferente era su pasado árabe y ese exotismo es precisamente lo que buscaron los viajeros extranjeros durante el siglo XIX. A la "leyenda negra" (promovida por una pujante Inglaterra protestante en pugna con un imperio católico Español) forjada en los siglos XVI y XVII se sumaba la imagen oriental de España desarrollada por los escritores románticos. La tradición literaria de los viajeros ingleses, franceses y americanos decimonónicos sentó las bases de la construcción textual del viaje a España. Theóphile Gautier, Byron, Mérimée, Chateaubriand, el vendedor de Biblias George Borrow, Washington Irving, Ford, Sarmiento y otros muchos participaron en esta construcción de la España romántica que estaba teñida de orientalismo meridional, unas veces con tintes hispanófilos, otras - tal vez las más - hispanófobos. Todo ello producía, como resultado, la imagen de España como el "otro" europeo. En su libro Viajes por Europa, Africa y América (18451847) (1993), el argentino Domingo Faustino Sarmiento explicaba así las costumbres españolas, sintetizando el sentir de muchos viajeros románticos: "el español de hoy es el árabe de ayer, frugal, desenvuelto, gracioso en la Andalucía, poeta i ocioso por todas partes; goza del sol, se emborracha poco i pasa su tiempo en las esquinas, figones i plazas" (Sarmiento 1993: 165). Al identificarse a los españoles con los árabes y los gitanos en la imaginación romántica, muchas de los estereotipos proyectados para estos grupos se 
atribuían a España como conjunto: primitivismo (que encandilaba a los románticos roussonianos), superstición, ignorancia; mezclados con la pasión desbordada por la música y el baile (Colmeiro 2002: 133).

La tradición literaria y artística que representaba a los españoles con rasgos físicos y morales propios de las regiones meridionales y orientales (MacKay 2006, Boone 2007) respondía a su vez a categorizaciones de la literatura científica y pseudocientífica producida en Europa y en Norte América (Pratt 1992). Ciertas fisonomías habían estado asociadas durante siglos con rasgos morales y hábitos como la pereza e indolencia que caracterizaban, desde una perspectiva eurocentrista, a muchos pueblos no europeos. En muchos libros de viajes, y textos afines, los españoles era objeto de esta caracterización negativa.

Si bien los diferentes gobiernos españoles habían pugnado por décadas (y siglos) por quitarse de encima el sambenito de país perezoso y sin industria (caracterización que recibía España por la doble vertientes de la leyenda negra y el orientalismo romántico), el pasado musulmán, no obstante, fue enfatizado por el aparato publicitario del régimen en sus primeros años. El entrenamiento y educación de los guías turísticos, por ejemplo, enfatizaba la historia y el arte medieval, prestando especial atención a la influencia árabe (Pack 2006: 61).

Luis Calleja, que tuvo una posición importante en la DGT durante las campañas publicitarias de la inmediata posguerra (y a quien algunos atribuyen la invención del lema "Spain is different"), escribió en su Apología turística de España (1943):

Centuries of Muslim penetration left behind on the land and in the Spanish spirit highly visible traits, sufficient to distinguish this country from the rest of Europe for its essence of difference (citado en Pack 2006: 67).

Pero en los cincuenta se decidió que era más importante subrayar la pertenencia de España a Europa. En esta misma insistencia se evidencia el afán de integrar a España en Europa y las dificultades de la integración. No en vano 1955, el año en que aparece el libro de Víctor de la Serna, es el mismo en que España entra finalmente en la ONU (en 1945 no había sido aceptada) y da fin a la política económica de autarquía y aislamiento que había dominado los primeros años de la posguerra. Solo cuatro años antes, en 1951, España ingresaba en la OMS y recibía el primer préstamo financiero de los EE. UU. (España había sido excluida del Plan Marshall en 1948).

La literatura de viajes de Víctor de la Serna se preocupa por establecer una continuidad cultural y étnica entre el norte de Europa y España. Una comparación repetitiva es la de los pueblos de España con otros pueblos de Europa. He aquí un ejemplo: “León parece una ciudad de la marca renana. No sé por qué, pero lo parece. ¿Aquistrán? ¿Tréveris? ¿Y si lo que pasa es que Aquistrán y Tréveris se parecen a León? De todos modos, esto es Europa, esto es Occidente" (Serna 1955: 114). 
Igualmente, la referencia a la procedencia étnica del pueblo español es una constante a lo largo de la obra. En sus largas excursiones muy pocas veces nos muestra Víctor de la Serna su interacción con los lugareños, pero sucede que cuando describe su apariencia física, esta responde a una misma y repetitiva descripción que es la que sigue: "al borde de la carretera he visto una chiquilla rubia, blanca, con unas trenzas como panojas de maíz dorado y aire de princesa aria" (1955: 77). Bien describa a los vaqueiros asturianos (1955: 234) o a las mozas y señoras de León "de un rubio ligeramente germánico" (1955: 114 y 117), o de los hidalgos de Cantabria "rubios y fornidos, de lo que es vestigio una raza de una belleza antropológica sorprendente" (1955: 248), nunca deja de pasar por alto los rasgos que manifiestan su "pureza racial goda": el cabello rubio germánico y los ojos azules. Víctor insiste en presentar las regiones que visita (Asturias, Cantabria, Norte de Castilla) como el reducto que fue capaz de preservar la pureza racial y cultural hispana, identificándola con lo visigodo y lo auténtico español. En su distinción entre lo español puro (visigótico-ario) y lo judío o árabe, coincide el autor con la visión oficial que ofrece el régimen resucitando el ideal monocultural y monoétnico de los reyes católicos.

Durante el Franquismo, los medios de comunicación oficiales hicieron un esfuerzo por producir textos publicados en inglés desdiciendo la imagen que había cuajado la literatura viajera decimonónica. Así, por ejemplo, Herbert W. Serra Williamson publicó The Tourist Guide-Book of Spain (1952) en el cual se incluía esta sección que trataba de la imagen de los españoles:

Southern Spaniards are known throughout the world for their dark complexion, but this apparently widespread conjecture is wrong, and 90 per cent in the Canary Island and some 73 per cent in Zamora are not so brown as is generally thought. According to army statistics, the average height of the Spanish soldier is about 1.635 meters ( $\left.5^{\prime} 6^{\prime \prime}\right)$, and this also contradicts the general idea that the Spaniards are rather short in statue because they exceed the average height of the Frenchman, Roumanian and Georgian (Williamson 1952: 14)

Con mayor insistencia, Víctor de la Serna notaba una y otra vez la estatura y la complexión clara de los habitantes de las regiones del norte de España que él visitaba. Así se encontraba en Palencia "con la mejor sangre goda en los ojos claros y el pelo rubio de la gente labriega, que en la frente preservada por el bies del sombrero descubre la tez rosada de la estirpe germánica" (1955: 65).

Apenas hay en el libro una descripción física que se corresponda al tipo mediterráneo, mientras que las referencias a los rasgos germánicos se multiplican, algunas veces con explicaciones prejuiciosas. Así, por ejemplo, se refiere a los vaqueiros de alzada (de la región de Asturias):

Conservaron la pureza racial goda más que sus compatriotas. Por eso la inmensa mayoría de estos pueblos-si se les puede llamar así-son rubios y de ojos azules. La sangre de Levante no ha llegado a ellos. Ni la sangre ismaelita (Serna 1955: 234). 
Frente a la descripción orientalizada de los españoles, canonizada en la literatura europea y extranjera de viajes del siglo XIX, presenta Víctor de la Serna su libro, reivindicando los primores de la pura raza española, la "no intoxicada" por los pueblos del sur.

Llama la atención, y es necesario incidir en este punto, que algunos de los escritores del realismo social hicieron lo contrario, poniendo énfasis en la presencia árabe en España y alabando su industria. Así lo hace Goytisolo en su libro de viajes Campos de Níjar (situado en Andalucía), y lo hará en muchos de sus posteriores libros. Goytisolo es, en cuanto a sus apreciaciones étnicas, todo lo opuesto a Serna y su defensa de la pureza de sangre goda hispana. Goytisolo insiste en la "fisonomía africana" (1960: 112) de los lugareños con quienes se encuentra así como en la continuidad del paisaje sahariano con el del sur peninsular (algo que, por otra parte, ya había observado Azorín en su artículo "España y África") y en el valor de su legado industrial y cultural en España.

Por supuesto, insistir en la pureza visigoda de la España visitada no forma parte solo de una cuestión étnica o fisonómica, sino religiosa. En el libro de Víctor de la Serna hay una constante exaltación de los valores católicos que el régimen ha identificado como parte de su política de afirmación de identidad nacional. Víctor de la Serna se refiere frecuente en sus escritos a los "cristianos viejos" y a su "limpieza de sangre" usando clasificaciones que provienen directamente de la España de los siglos de Oro, de donde derivaba mucha de la temática, imaginería y símbolos nacionalistas empleados por el franquismo. A los auténticos y originales españoles se refiere insistiendo en su fisonomía (rubios de ojos claros), en su etnia (de ascendencia visigoda, o también romana), en su religión (cristianos viejos) o grupo social (hidalgos).

El viaje de Víctor de la Serna, que sigue la ruta de los foramontanos y también la de la Reconquista, está jalonado de visitas a lugares clave en la identidad católica nacional, destacando entre ellos Astorga, sede del Obispado "de los más antiguos y extensos de España" (1955: 146) o el Monasterio de Santo Toribio, en Potes "el mayor santuario de la Cristiandad" que guarda "la mayor reliquia del mundo" (1955: 184), un fragmento de la cruz de Cristo.

Los personajes históricos mencionados en el libro también apuntan hacia esa afirmación de lo católico. Se ensalzan figuras históricas como la de la Reina Isabel la Católica, una "castellanita rubia" que era "una de las mujeres más cultas de Europa" (1955: 63), o el Cid, "el hombre más valeroso y entero de la raza" (1955: 76). Igualmente, relata anécdotas de otros representantes del espíritu católico español, como Carlos $\mathrm{V}$ y otros monarcas españoles.

Con respecto a las minorías étnicas de la España Medieval, los árabes no son reconocidos de manera individual, el autor se refiere a ellos en muchas ocasiones genéricamente como "el moro". Por otro lado, menciona brevemente a don Sem Tob, un escritor judío, pero de él escribe, con cierto deje de orgullo, que de su obra "no sabemos una sola estrofa todos los españoles" (1955: 85). Víctor de la Serna claramente prefiere a los visigodos católicos, los "auténticos 
españoles", y su historia es la que se celebra página tras página. Sin embargo, sería injusto no reconocer que el autor, en una ocasión extraordinaria, muestra, a su manera, simpatía por los judíos sefarditas: "Buena gente, lector. Yo me los he encontrado por el mundo y son hospitalarios, honestos y creyentes. Y ellas son muy guapas" (1955: 55).

Además de ensalzar figuras emblemáticas de la mitohistoria católica (y restar valor a las minorías religiosas por su "otredad"), Víctor de la Serna traza un genealogía del pensamiento ilustrado religioso, en la cual destaca al ilustrado Padre Feijoo, a quien pone como perfecto ejemplo del equilibrio entre la pureza de la fe, "con su ingente sabiduría teológica y moral" (1955: 136), y la confianza en la ciencia. En el mismo capítulo arremete de nuevo contra los Krausistas (esta vez los nombra: Azcárate, Giner, Cossío) y los acusa de haber introducido una pseudociencia semilaica, la Pedagogía, que con sus "cursillos y vacaciones ilustradas" pretende sustituir una buena educación católica. En otro lugar hay un reconocimiento al poeta oficial del régimen, Leopoldo Panero (“iUn poeta como un castillo, me valga Dios!” [1955: 143]).

De esta manera, las reflexiones y juicios desperdigados a lo largo de las páginas del libro se convierten en un muestrario de las figuras históricoculturales que entraban -o no- dentro del canon ortodoxo de la época.

\section{LA ESPAÑA INDUSTRIAL Y MODERNA}

Con respecto a la situación política, hubo un intento gubernamental por hacer que Europa aceptara y viera con buenos ojos el régimen. Así el régimen facilitaba la labor a escritores extranjeros de libros y guías de viajes que estuvieran dispuestos a ofrecer una visión positiva del estado actual. La clave era convencer al posible turista de que España era un país moderno y pacífico.

Un ejemplo de esta política publicitaria es el autor Temple Fielding, para quien la Dirección General de Turismo de España puso a su disposición un chófer y le ofreció otras cortesías durante sus visitas (Pack 2006: 58). El libro Travel Guide to Europe (1952), de Fielding, vio sucesivas ediciones a lo largo de la década de los cincuenta. El capítulo dedicado a España es una celebración de la modernidad española:

Forget about the popular stereotype of the peon asleep in the sun, with his sombrero over his eyes; in today's hopped-up economy, the siesta is completely ignored by millions of citizens, while others take it only during the hottest days of summer. As for the hygienic aspects, the Iberians are almost always meticulous about bathing, neat in dress, and spotless in their kitchens; in this regard, they are so far ahead of the French and the Italians (Fielding 1952: 729).

Con respecto al régimen dictatorial, Fielding difuminaba los miedos que los turistas americanos pudieran tener y afirmaba que, al contrario de lo que ocurría en los países del eje comunista, en España "you can go exactly where you wish, do exactly what you choose, and say exactly what you feel about the 
government or anything else" (1952: 729). Con una caracterización tan positiva de los españoles y de la dictadura, no sorprende que la guía de Fielding se convirtiera en una de las guías favoritas de la Dirección General de Turismo.

Víctor de la Serna también quería dejar constancia del nivel de desarrollo y modernidad del país. Una vez más, su interés es paralelo al del régimen, y su libro funciona como instrumento propagandístico. El Plan Nacional de Turismo (1952) se enfocaba en dos aspectos que consideraba especialmente relevantes de España: su tradición artística y su modernidad industrial:

Spain needs to become known not only as an immense museum of the artistic treasures of our ingenuous forefathers, but also as a modern people, open to all initiatives and receptive to all suggestions (citado en Pack 2006: 66).

En sintonía con las directrices marcadas por la nueva campaña publicitaria del régimen, Víctor de la Serna camina ese sendero: los dos temas constantes en su libro son el pasado glorioso y el presente industrioso. El pasado glorioso es parte fundamental del libro, con las enfáticas descripciones de monumentos, curiosidades históricas llenas de blasones y linajes, desaforados elogios de autores y artistas, enfundados en una prosa ágil y pomposa.

Más interesante aún es su retrato del presente industrioso del país. En muchos de los destinos a los que llega el escritor, no ahorra elogios a la hora de ensalzar los logros en el progreso en campos como la industria siderúrgica o minera, la educación, las comunicaciones y los servicios sanitarios en las zonas visitadas. El autor es prolijo en números y estadísticas para probar la efectividad y empuje del desarrollo español, también describe minuciosamente los rasgos de progreso. Cuando llega a Valdeón, un pueblo de la cornisa cantábrica, en el corazón de los Picos de Europa, exclama: “Hay una estación radiotelegráfica, así como no hay analfabetos, y así como hay una fonda con calefacción y habitaciones con baño y agua caliente" (1955: 152).

El tema de la educación y la alfabetización de los españoles es una constante, la villa de Saldaña se describe como "muy letrada y la gente sabe mucho por allí". En el Valle de Babia, igual que en Valdeón, "no hay analfabetos" y además los pueblos de la zona presentan un "aspecto de supercivilización". Algunas veces se llega a la idealización, recurriendo a imágenes de arcadia pastoril, así por ejemplo el Valle de Babia es un "trozo arcádico de tierra española" (1955: 125), y el cercano Valle de la Libertad es un "medio idílico" (1955: 133). En otro pueblo asturiano se deja llevar de nuevo el viajero por la euforia del progreso: "Son treinta casas escasamente, pero hay hasta peluquería de señoras. Todo el mundo vive bien, viste bien, tiene bicicletas, aparato de 'radio', máquina de coser y gabardina. Signos todos de bienestar y casi de hidalguía" (1955: 221).

Serna es un escritor ingenioso que es capaz de transformar las carencias en virtudes. Así por ejemplo, al visitar un pueblo aislado que no tiene más comercio que una abigarrada tienda de ultramarinos escribe: "Hay que saber lo 
que es la tienda en estos cruces de caminos: es todo, es la civilización, el enlace con el mundo. En un país culto como éste, donde no existen analfabetos, es biblioteca y museo y ágora" (1955: 123).

Al contraste con las estadísticas que existen de la época, los datos aportados por Víctor de la Serna despiertan desconfianza: al comienzo de los años sesenta el analfabetismo real en España no descendía del 30 por ciento de la población (Roig López 2002: 53).

\section{VALORACIÓN DEL RÉGIMEN: “ESOS SEÑORES DE MADRID SON BUENA GENTE”}

Aunque la mirada positiva del autor ensalza y encomia cuanto ve, en algunas ocasiones Víctor de la Serna encuentra $-\mathrm{y}$ describe - situaciones y problemas que son motivo de preocupación. Ese es el caso en su visita al Valle de Luna (León), donde refiere la triste historia de varios pueblos que han sido anegados para la construcción de un pantano. El autor no llega a presentar la voz de los habitantes afectados (algo que harían más tarde los escritores del realismo social), pero sí reconoce que la decisión del gobierno ha perjudicado a estos aldeanos. Sin embargo, el autor reconforta al lector asegurándole un final feliz para los desalojados de sus tierras: "Estate seguro de que esto de las expropiaciones de tierras y de paisajes se ha de arreglar algún día. Estos señores de Madrid son muy buena gente" (Serna 1955: 124).

Un caso similar está descrito en su segundo libro de viajes. Aquí se retrata la próspera industria que rodea el pueblo de Puertollano (que hoy en día es el centro industrial más grande de la región de Castilla-La Mancha). El autor describe con fascinación las pertenencias mineras de la compañía Francesa de Peñarroya, pero con más admiración incluso las "instalaciones fabulosas" que son los pozos petrolíferos de la Empresa Nacional Calvo Sotelo, y también la central termoeléctrica. También nota las características del "paradisíaco poblado de la Empresa Nacional Calvo Sotelo, un oasis de verdor, [...] Chalets maravillosos, casitas como de cuentos de Grimm, piscinas, iglesias, escuelas, teatro, [...] ¡Y agua! Agua abundante, dulce, fresca..." (Serna 1959: 156). Sin embargo, entre tanta industria y modernidad, el autor no puede evitar mencionar que, muy cerca del maravilloso poblado y de la central eléctrica, la villa de Puertollano - con cuarenta mil habitantes - no tiene agua corriente, o en el pueblecito cercano de Villar - formado por sesenta familias - no hay luz eléctrica. El autor se atreve a plantear (aunque lo hace entre paréntesis) lo que puede ser una injusticia social: “(Oye, compañero, ¿por qué no llegará todavía el agua del montoso también a las casas de Puertollano?)". Él mismo responde a su interrogación; para calmar los ánimos y transmitir tranquilidad al lector, escribe: "¿Será que falta dinero? Yo creo que al llegar a Madrid debiéramos pedirlo: a lo mejor, como esos señores son tan buena gente, lo dan" (Serna 1959: 157). Lo mismo ocurre cuando denuncia el vergonzoso estado de abandono de las ruinas de una basílica paleocristiana (Serna 1959: 168). “Verás lo que tardan 
nuestros amigos de Madrid en salvar la pila bautismal más antigua de España. Verás lo que tarda en saltar de ira [...] nuestro santo compañero de la prensa, don Ángel Herrera, obispo de Málaga" (Serna 1959: 170). Consciente de que está al borde de pintar la "España negra", tranquiliza a su lector con estas palabras: "te prometo, compañero, no volver a ver cosas feas en nuestro viaje".

En todos los casos de lo que pudiera considerarse denuncias de injusticias y abandonos, el autor ha dejado claro que los buenos señores de Madrid (o los santos del obispado) sabrán resolver la situación. Se trata de un estilo muy diferente al de la desesperanzada denuncia que habían practicado algunos regeneracionistas y que volverá a ser el tono común de la literatura viajera social de los sesenta. El viajero aquiescente del franquismo transmite al lector confianza en los gobernantes y en su plan de desarrollo. Sin embargo, a pesar de la certidumbre y la ilusión con que Víctor de la Serna describía el país y auguraba un pronta solución para los ocasionales desarreglos, su visión no caló en un grupo de escritores más jóvenes y contestatarios. Se trataba de Goytisolo, Ferrés, López Salina, Torbado; una nueva generación de escritores viajeros que recuperó la circunspección, desasosiego y afán de denuncia krausista. Quince años después de publicarse el primer libro de viajes de Víctor de la Serna, Jesús Torbado escribía lo siguiente en su libro de viajes Tierra mal bautizada (1969):

Solamente algún viajero imaginativo como Víctor de la Serna ha visto en Tierra de Campos jardines que no existen, maravillas geográficas irreales y glorias pasadas. Solamente los poetas optimistas han descubierto un "paisaje literario" tan cruelmente falso que acongoja a cuantos han visto el verdadero paisaje (Torbado 1969: 154).

Igual que Torbado, muchos otros practicaron una literatura viajera de denuncia que renegaba de los "poetas a sueldo" (Torbado 1969: 113) empeñados en maquillar la dramática soledad de tantos pueblos abandonados. Otro ciclo comenzaba donde ese extraordinario palimpsesto que es el género de los libros de viajes se dilataba en un nuevo duelo de escrituras y reescrituras.

En conclusión, es imprescindible conocer los libros de Víctor de la Serna para comprender la batalla ideológica que se libró, en la década de los cincuenta y sesenta, entre los autores de libros de viajes que plasmaban versiones enfrentadas de una única realidad. Los libros de viajes de Víctor de la Serna se constituyeron en vehículo apropiado para diseminar el mensaje del régimen y su proyecto de nación en una coyuntura histórica - el comienzo del boom turístico - que habría de transformar el país para siempre. Quedan aún por analizar más textos de otros "viajeros aquiescentes del franquismo"; solo entonces se conocerá en toda su extensión este peculiar maridaje entre dictadura, turismo y libros de viaje. 


\section{BIBLIOGRAFÍA}

ANDERSON, B. (1984), Imagined Communities: Reflections on the Origins and Spread of Nationalism, Londres, Verso.

AzOrIN (1968), Tiempo y paisaje. Visión de España, Madrid, Ediciones Cultura Hispánica.

BURGO, J. (1963), La aventura hispánica de los viajeros extranjeros del siglo XIX y la España desconocida, Pamplona, Editorial Gómez.

BoOne, M. E. (2007), Vistas de España. American Views of Art and Life in Spain, 1860-1914, New Haven y Londres, Yale University Press.

ColmeIro, J. F. (2002), “Exorcising Exoticism: Carmen and the Construction of Oriental Spain", Comparative Literature 54, 2: 127-144.

CHAmpeau, G. (2004), "Viajar bajo el franquismo. Relato polémico y escritura del yo", Quimera 246-247; 76-81.

FIELDING, T. H. (1952), Travel Guide to Europe, Nueva York, William Sloane.

GIFRA-ADrOHER, P. (2000), Between History and Romance. Travel Writing on Spain and the Early Nineteenth-Century United States, Madison, Fairleigh Dickinson University Press.

GIL CASADO, P. (1973), La novela social española (1920-1971), Barcelona, Seix Barral.

GomeZ-MartineZ, J. L. (1975), Américo Castro y el origen de los Españoles: Historia de una polémica, Madrid, Gredos.

GoYTisOlO, J. (1960), Campos de Níjar, Barcelona, Seix Barral.

Holguin, S. (2002), Creating Spaniards, Madison, University of Wisconsin Press.

MACKAY, R. (2006), "Lazy, Improvident People", Myth and Reality in the Writing of Spanish History, Ithaca y Londres, Cornell University Press.

ORTEGA CANTERO, N. (1988), “La experiencia viajera en la Institución Libre de Enseñanza", Viajeros y paisajes, Gómez Mendoza J., Ortega Cantero, et al., Madrid, Alianza Editorial, 67-88.

PACK, D. (2006), Tourism and Dictatorship, Londres, Palgrave Macmilian.

PRATT, M. L. (1992), Imperial Eyes. Travel Writing and Transculturation, Londres y Nueva York, Routledge.

RiBBANS, G. (1987), "Spanish Nacional Pride and Foreign Travelers in the Eighteenth Century", Dieciocho 10.1: 3-17.

RoIG LOPEZ, O. (2002), “La institución educativa española desde la postguerra hasta la transición. Iglesia y tecnología", Tesis doctoral, Universitat Autònoma de Barcelona.

SARMiento, D. F. (1993), Viajes por Europa, Africa y América 1845-1847 y Diario de gastos, Fernández, J. (ed.), Buenos Aires, Fondo de Cultura Económica.

SERna EsPINA, V. (1955), Nuevo Viaje de España. La Ruta de los Foramontanos, Madrid, Prensa española, 1955.

Serna EspinA, V. (1959), Nuevo Viaje de España. La Vía del Calatraveño, Madrid, Prensa española.

SERNA EsPINA, V. (1965), España, compañero, edición y prólogo de Alfonso de la Serna, Madrid, Prensa española.

SERRA WiLliamsOn, H. M. (1952), The Tourist Guide-Book of Spain, Madrid, Londres y Nueva York, The Times of Spain, 1952.

TORBADO, J. (1969), Tierra mal bautizada, Madrid, Emiliano Escolar.

UMBRAL, F. (1999), "Víctor de la Serna", El Mundo, 13 de enero. 